\title{
GX15-070 (obatoclax) overcomes glucocorticoid resistance in acute lymphoblastic leukemia through induction of apoptosis and autophagy
}

\author{
N Heidari ${ }^{1}$, MA Hicks ${ }^{1}$ and $\mathrm{H} \mathrm{Harada}^{*, 1}$
}

Glucocorticoids (GCs) are common components of many chemotherapeutic regimens for lymphoid malignancies including acute lymphoblastic leukemia (ALL). The BCL-2 family has an essential role in regulating GC-induced cell death. Here we show that downregulation of antiapoptotic BCL-2 family proteins, especially MCL-1, enhances GC-induced cell death. Thus we target MCL-1 by using GX15-070 (obatoclax) in ALL cells. Treatment with GX15-070 in both dexamethasone (Dex)-sensitive and -resistant ALL cells shows effective growth inhibition and cell death. GX15-070 induces caspase-3 cleavage and increases the Annexin V-positive population, which is indicative of apoptosis. Before the onset of apoptosis, GX15-070 induces LC3 conversion as well as p62 degradation, both of which are autophagic cell death markers. A pro-apoptotic molecule BAK is released from the BAK/MCL-1 complex following GX15-070 treatment. Consistently, downregulation of BAK reduces caspase-3 cleavage and cell death, but does not alter LC3 conversion. In contrast, downregulation of ATG5, an autophagy regulator, decreases LC3 conversion and cell death, but does not alter caspase-3 cleavage, suggesting that apoptosis and autophagy induced by GX15-070 are independently regulated. Downregulation of Beclin-1, which is capable of crosstalk between apoptosis and autophagy, affects GX15-070-induced cell death through apoptosis but not autophagy. Taken together, GX15-070 treatment in ALL could be an alternative regimen to overcome glucocorticoid resistance by inducing BAK-dependent apoptosis and ATG5-dependent autophagy.

Cell Death and Disease (2010) 1, e76; doi:10.1038/cddis.2010.53; published online 16 September 2010

Subject Category: Cancer

Glucocorticoids (GCs) are common components in many chemotherapeutic protocols for lymphoid/myeloid malignancies, including acute lymphoblastic leukemia (ALL). However, patients often develop resistance to GCs on relapse. Resistance to GCs in ALL can be associated with defects in apoptosis machinery and not in the GC receptor. ${ }^{1-4}$ Thus, targeting downstream molecules may lead to the development of new therapeutic strategies. GC-induced apoptosis is through the intrinsic mitochondria-dependent pathway. ${ }^{5-7}$ The BCL-2 family proteins are central regulatory proteins in this pathway. ${ }^{8,9}$ The BCL-2 family is subdivided into three main groups based on regions of $B C L-2$ homology $(B H)$ and function: multi-domain antiapoptotic (e.g., BCL-2, MCL-1, BCL- $X_{L}$ ), multi-domain pro-apoptotic (e.g., BAX, BAK), and BH3-only pro-apoptotic (e.g., BAD, BID, BIM, PUMA). $\mathrm{BH} 3-$ only proteins cause cytochrome $c$ release by activating BAX and/or BAK, while the antiapoptotic BCL-2 family of proteins prevents this process. ${ }^{10,11}$ Targeting the BCL-2 family proteins might be a strategy to overcome GC resistance. We and others have shown that BIM, a pro-apoptotic $\mathrm{BH} 3-$ only protein, is upregulated by dexamethasone (Dex) treatment in ALL cells and has an essential role in Dex-induced apoptosis. ${ }^{12}$ We then have demonstrated that co-treatment with Dex (for BIM upregulation) and MEK/ERK inhibitors (for BIM dephosphorylation/activation) promotes apoptosis in a variety of ALL cells. ${ }^{9} \mathrm{GC}$ resistance is also derived from aberrant changes in the regulation of antiapoptotic proteins. Recent studies have shown that increased expression of MCL-1 is associated with GC resistance. ${ }^{13-15}$ MCL-1 is distinct among other antiapoptotic proteins, with its short protein turnover being regulated by the $26 \mathrm{~S}$ proteasome. $^{16}$ Thus, downregulation or inactivation of MCL-1 could be attractive to resensitize the chemotherapeutic response in ALL.

Recently, small molecules that directly interact with antiapoptotic BCL-2 proteins have been developed. ${ }^{17,18}$ These agents interact with antiapoptotic BCL-2 family proteins at their $\mathrm{BH} 3$-binding grooves and mimic the action of $\mathrm{BH} 3-o n l y$ proteins. Among the small-molecule antagonists of antiapoptotic BCL-2 family proteins, GX15-070 (obatoclax), which is an indole bipyrrole compound, exhibits potency against MCL-1. ${ }^{19,20}$ Although GX15-070 is currently used in developing single-agent therapy or in combination in phase I/II clinical trials directed at leukemia, ${ }^{21,22}$ the molecular mechanisms of cell death induced by GX15-070 are not entirely clear. Some recent reports suggest the induction of autophagy and

\footnotetext{
${ }^{1}$ Department of Internal Medicine, Massey Cancer Center, Virginia Commonwealth University, Richmond, VA, USA

${ }^{*}$ Corresponding author: H Harada, Department of Internal Medicine, Massey Cancer Center, Virginia Commonwealth University, 401 College Street, Richmond, VA 23298, USA. Tel: 804628 0064; Fax: 804827 1276; E-mail: hharada@vcu.edu

Keywords: glucocorticoid; obatoclax; apoptosis; autophagy; acute lymphoblastic leukemia; MCL-1

Abbreviations: GC, glucocorticoid; GX, GX15-070; ALL, Acute lymphoblastic leukemia; Dex, dexamethasone; BH, BCL-2 homology; PI3K III, class III phosphoinositide 3-kinase

Received 22.4.10; revised 02.8.10; accepted 11.8.10; Edited by G Melino
} 
other cell death pathways besides caspase-dependent apoptosis by $\mathrm{GX} 15-070 .^{23-28}$

A major form of autophagy is macroautophagy, in which parts of the cytoplasm and intracellular organelles are sequestered within a double autophagic membrane. Autophagosome formation is dependent on the interaction and activity of ATG proteins. Lipid-protein and protein-protein conjugations occur during autophagosome formation. One of the important conjugations is between cleaved ATG8/LC3 and phosphatidylethanolamine. This conjugation is an event to form an autophagosome structure and can be used as an autophagy marker. In the second conjugation event, ATG12 covalently binds to ATG5. ATG5 then associates with ATG16, which is required for autophagosome elongation. Beclin-1/ ATG6 has a role in the initiation of autophagy, by its interaction with class III phosphatidylinositol-3 kinase. ${ }^{29}$ Furthermore, Beclin-1 has been reported as a $\mathrm{BH} 3$-only protein interacting with BCL-2 and BCL- $X_{L}$, indicating that it is capable of crosstalk between autophagy and apoptosis. ${ }^{30}$

In this study, we show that GX15-070 induces cell death through BAK-dependent apoptosis and ATG5-dependent autophagy not only in Dex-sensitive, but also in Dex-resistant ALL cells. Thus, GX15-070 treatment in ALL could be an alternative regimen to overcome $\mathrm{GC}$ resistance.

\section{Results}

Downregulation of MCL-1 enhances Dex-induced lethality in ALL cells. We and others have previously shown that BIM, a pro-apoptotic BH3-only protein, has an essential role in executing Dex-induced cell death in ALL cells. BIM is capable of interacting with all antiapoptotic BCL-2 family proteins (i.e., BCL-2, BCL- $X_{L}, M C L-1, B C L-w$, and $A 1$ ). To examine whether these antiapoptotic molecules have a specific role in Dex-induced apoptosis, we introduced shRNA for BCL-2 or MCL-1 into CCRF-CEM (CEM) T-ALL cells, and determined the effect on Dex-induced cell death. Downregulation of MCL-1 strongly enhanced apoptosis induced by Dex compared with the downregulation of BCL-2 (Figure 1). Downregulation of BIM showed significant reduction of Dex-induced apoptosis, as previously demonstrated. ${ }^{9}$ The results presented here and those of a previous publication ${ }^{31}$ suggest that inactivation of MCL-1 can sensitize Dex-induced cell death in ALL cells.

GX15-070 kills both Dex-sensitive and -resistant ALL cells. GX15-070 is a small compound that targets all antiapoptotic BCL-2 family proteins. The results in Figure 1 prompted us to examine whether GX15-070 induces cell death in ALL cells. We first determined the dose response of GX15-070 as a single agent for the induction of cell death and found that the concentration of $100 \mathrm{nM}$ showed effective cell death activity in CEM cells (data not shown). Co-treatment of Dex-sensitive CEM cells with $100 \mathrm{nM}$ Dex and $100 \mathrm{nM}$ GX15-070 showed an additive killing effect as compared with each treatment alone (Figure $2 a$ and b). We then treated Dex-resistant Molt-4, Reh, HSB-2, and Jurkat ALL cells with $100 \mathrm{nM}$ of GX15-070. GX15-070 inhibited cell proliferation and induced cell death (Figure $2 a$ and $b$ ).
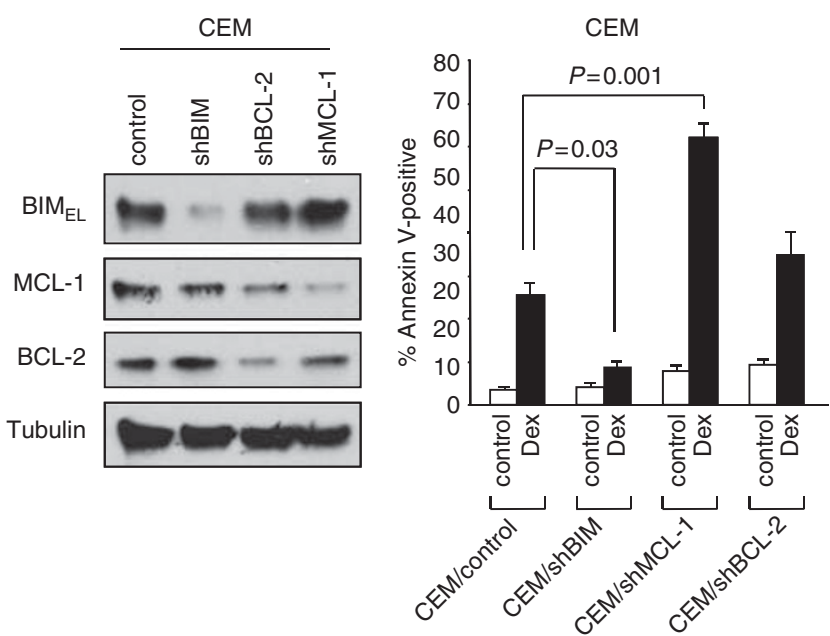

Figure 1 Downregulation of MCL-1 enhances dexamethasone-induced lethality. Left panel: CEM cells were infected with lentiviruses expressing shRNAs for non-targeting control, BIM, MCL-1, or BCL-2. Puromycin-resistant cells were pooled after each infection. Equal amounts of total cell extracts were subjected to western blotting with the indicated antibodies. Right panel: Cells were treated with $100 \mathrm{nM}$ Dex for $48 \mathrm{~h}$. The percentage of apoptotic cells was determined by Annexin V-propidium iodide (PI) staining followed by FACS analysis. Values represent the mean \pm S.D. of three independent experiments

In contrast to CEM cells, no additive effect was observed by co-treatment with Dex and GX15-070 in these cells. Thus, the results strongly indicate that $\mathrm{GX15-070}$ as a single agent is capable of overcoming Dex resistance in ALL cells.

GX15-070 induces apoptosis and autophagy. Increased population of Annexin V-positive cells (Figure $2 \mathrm{~b}$ ) indicates that cell death is induced by GX15-070 treatment. We further confirmed GX15-070-induced apoptosis by detection of caspase-3 and PARP cleavages in CEM cells (Figure 3a). To examine whether GX15-070-induced cell death is caspase-dependent, we added a pan-caspase inhibitor Z-VAD-FMK (Z-VAD) in GX15-070-treated CEM cells. Although caspase-3 and PARP cleavages were inhibited by Z-VAD (Figure 3a), total cell death induced by GX15-070 was not affected (Figure $3 b$ ). We thus examined whether other cell death pathways such as autophagy or caspaseindependent cell death were induced. The conversion from LC3-I to -II, which is indicative of autophagy, was observed with GX15-070 treatment in CEM, HSB-2, and Jurkat cells (Figure $3 a$ and $\mathrm{c}$ ). However, we could not detect LC3 conversion with Dex treatment in these cells, suggesting that autophagy induction is specific to GX15-070 treatment. Furthermore, following GX15-070 treatment, RFP-LC3 transfected into CEM cells displayed punctated particles that show autophagosome formation and conversion of LC3-I to -II (Figure 3d). AIF release in cytosol, indicative of caspase-independent cell death, was also detected with GX15-070 treatment (Figure 3e). Interestingly, by the addition of Z-VAD, LC3 conversion was not altered (Figure 3a) and AIF release was increased (Figure 3e), suggesting that blocking GX15-070-induced caspasedependent apoptosis by Z-VAD forced the cells to commit to caspase-independent apoptosis and autophagy. 

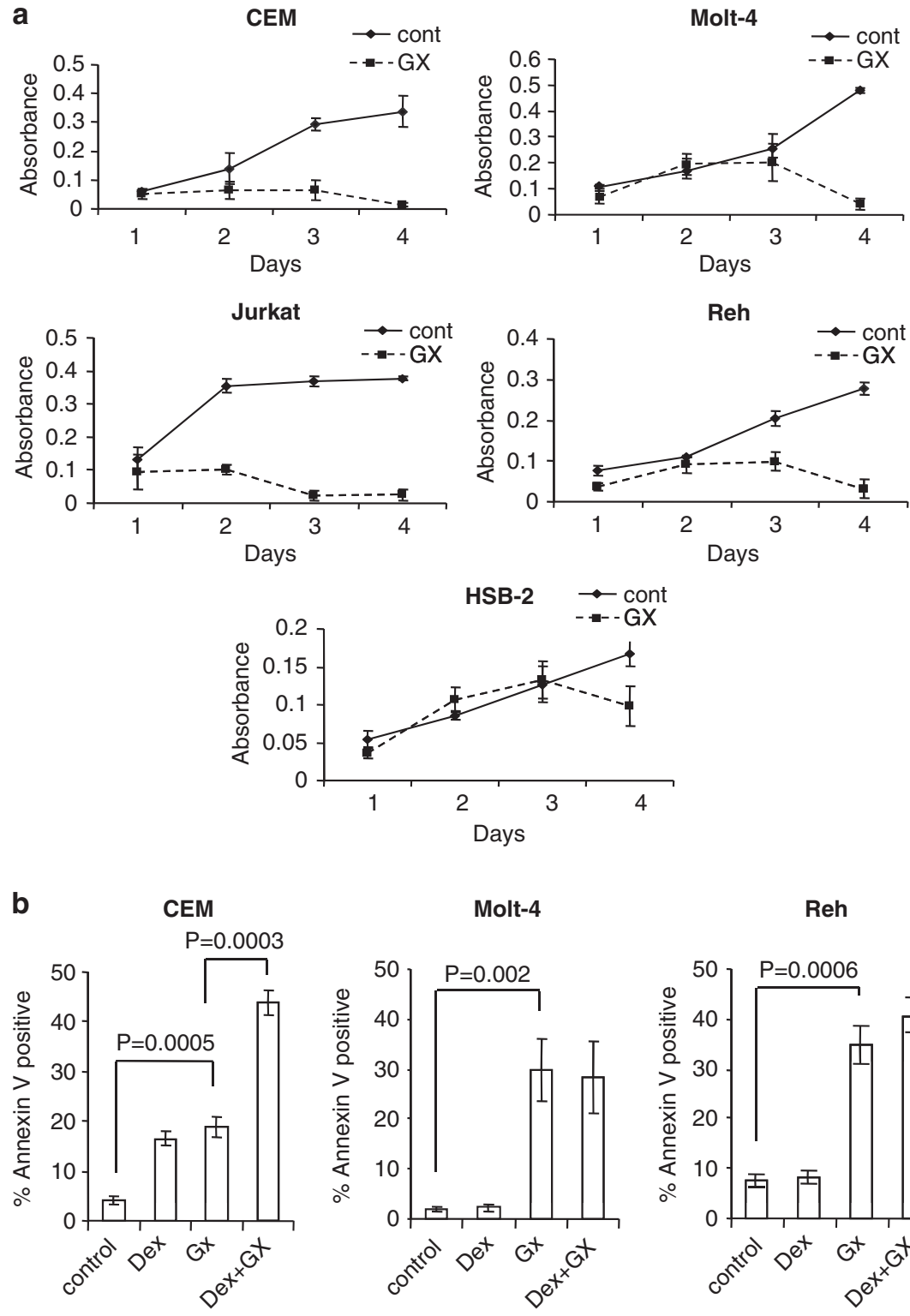

Molt-4

Reh
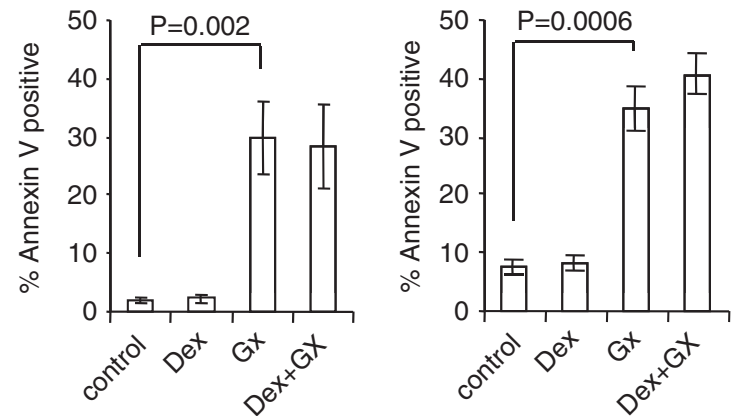

Jurkat

HSB-2
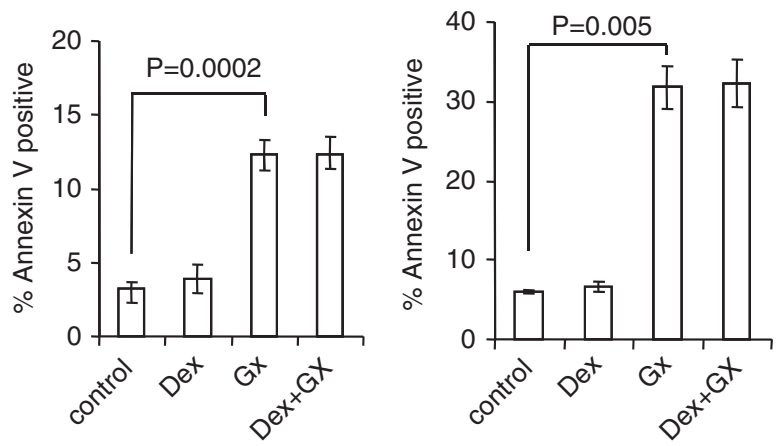

Figure 2 GX15-070 has lethality effect in both Dex-sensitive and -resistant ALL cells. (a) ALL cell lines including CEM, Molt-4, Jurkat, Reh, or HSB-2 were treated with $100 \mathrm{nM} \mathrm{GX15-070} \mathrm{(GX)} \mathrm{for} \mathrm{indicated} \mathrm{times} \mathrm{and} \mathrm{growth} \mathrm{rate} \mathrm{was} \mathrm{determined} \mathrm{by} \mathrm{WST-1} \mathrm{colorimetric} \mathrm{assay.} \mathrm{Error} \mathrm{bars} \mathrm{represent} \mathrm{the} \mathrm{standard} \mathrm{error} \mathrm{of} \mathrm{three} \mathrm{independent}$ experiments. (b) Cells were treated with $100 \mathrm{nM}$ Dex and/or $100 \mathrm{nM} \mathrm{GX15-070} \mathrm{for} 48 \mathrm{~h}$. The percentage of cell death was determined by Annexin V-PI staining followed by FACS analysis. Values represent the mean \pm S.D. of three independent experiments 
a

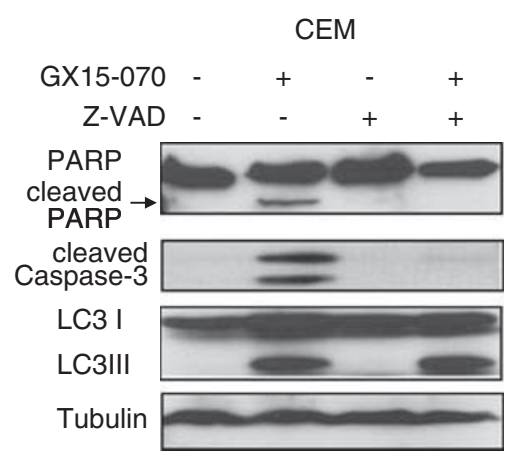

b

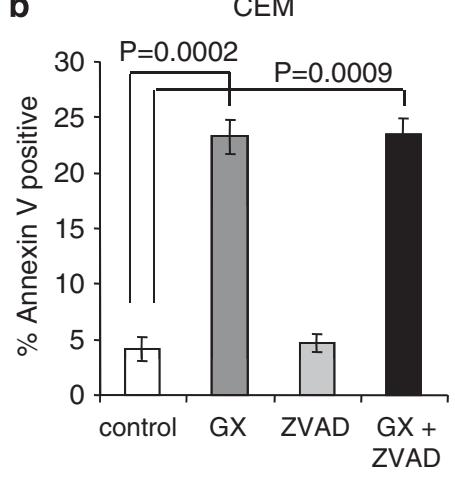

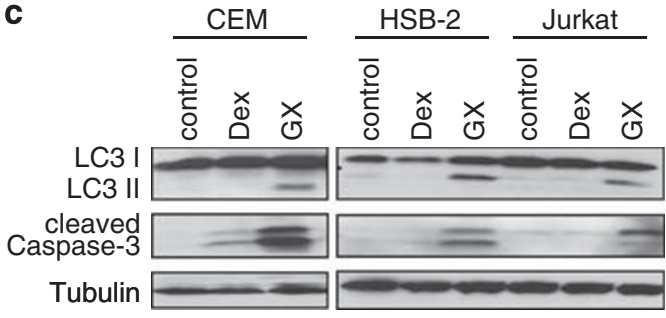

e

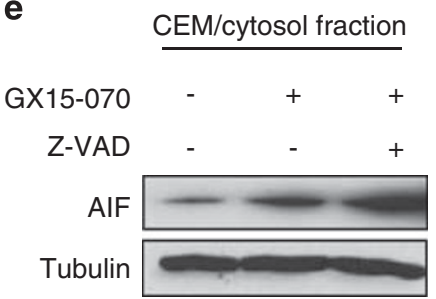

d

CEM-RFP-LC3/control
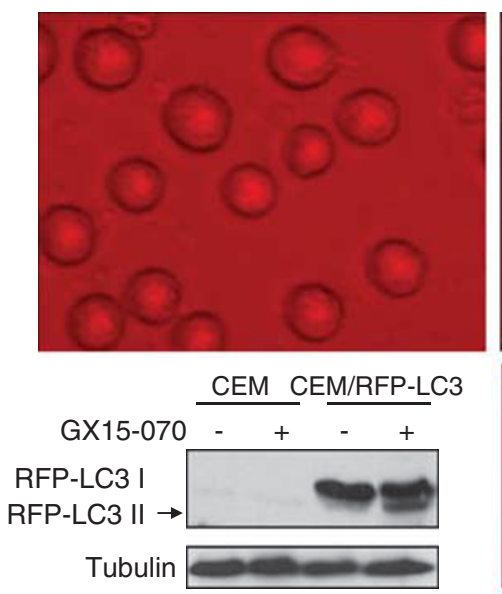

CEM-RFP-LC3/GX 24h
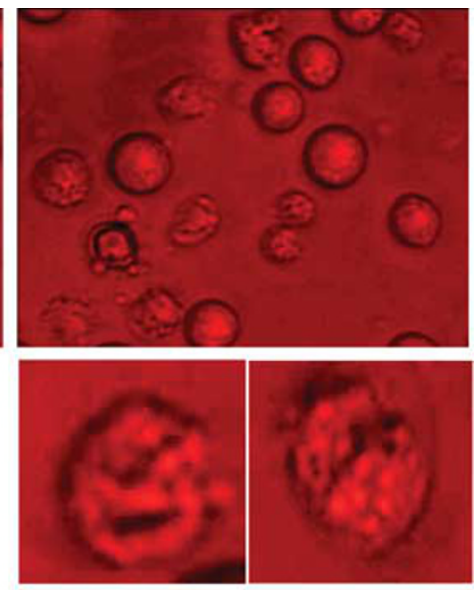

Figure 3 Apoptosis and autophagy are induced by GX15-070 treatment. (a) CEM cells were treated with $100 \mathrm{nM} \mathrm{GX15-070 \pm 50 \mu M} \mathrm{Z-VAD} \mathrm{for} 32 \mathrm{~h}$. Z-VAD was added 30 min before GX15-070 treatment. Cleavage of PARP or caspase-3 and LC3 conversion were detected by western blot analyses. (b) CEM cells were treated with $100 \mathrm{nM}$ GX15-070 in the presence or absence of $50 \mu \mathrm{M} Z$ Z-VAD for $48 \mathrm{~h}$. The percentage of cell death was determined by Annexin V-PI staining followed by FACS analysis. Values represent the mean \pm S.D. of three independent experiments. (c) Dex-sensitive CEM or -resistant HSB-2 and Jurkat cells were treated with $100 \mathrm{nM}$ Dex or $100 \mathrm{nM}$ GX15-070 for $24 \mathrm{~h}$, and LC3 conversion and caspase-3 cleavage were detected by western blot analyses. (d) CEM cells were stably transfected with RFP-LC3, and G418-resistant clone cells were then treated with $100 \mathrm{nM} \mathrm{GX15-070} \mathrm{for} 24 \mathrm{~h}$. Punctated RFP-LC3 was visualized under a fluorescent microscope. Western blot analysis confirmed the conversion of RFP-LC3. These pictures are representative of three independent experiments. Magnification is $\times 40$. Bottom pictures are enlarged single-cell images. (e) CEM cells were

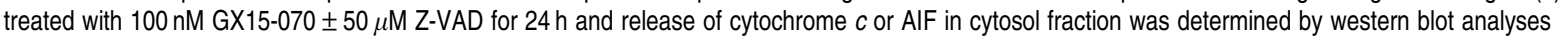

We next performed a time-course study to examine when autophagy and apoptosis started and proceeded by GX15-070 treatment. Autophagy judged by LC3 conversion was detected within $6 \mathrm{~h}$ after the treatment, while apoptosis judged by caspase- 3 cleavage was detected at the later time points (Figure $4 a$ and b). The most dramatic difference between the onset of autophagy and apoptosis was observed in Molt-4 cells. We also detected a massive decrease in p62 expression, which is another marker for autophagy (Figure 4b). ${ }^{29}$ Taken together, GX15-070 induces multiple cell death pathways such as caspase-dependent, -independent apoptosis, and autophagy.
GX15-070 induces BAK-dependent apoptosis in ALL cells. We further investigated the potential molecular mechanisms of how GX15-070 induces multiple cell death pathways. As BAK interacts with MCL-1 under normal condition and is released to be activated upon cell death stimuli, ${ }^{32}$ we examined the interaction of BAK with MCL-1 after GX15-070 treatment. We detected dissociation of BAK/MCL-1 at $5 \mathrm{~h}$ after treatment with GX15-070 (Figure 5a). Following the dissociation, we noticed that expression of MCL-1 was decreased at 16-24h, while the expression levels of BAX, BAK, BIM, BCL-2, and BCL- $X_{L}$ remained constant (Figure $5 b$ ). Cleaved MCL-1 was increased in accordance with decrease of 
full-length MCL-1 (Figure 5c). Addition of MG-132, a proteasome inhibitor, restored the level of MCL-1 from GX15070-mediated degradation (Figure 5d), suggesting that the degradation of MCL-1 is proteasome-dependent.

a

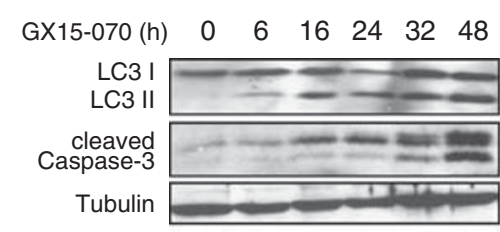

HSB-2

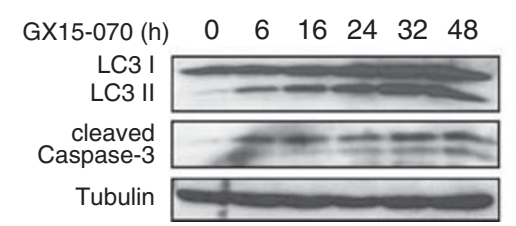

b

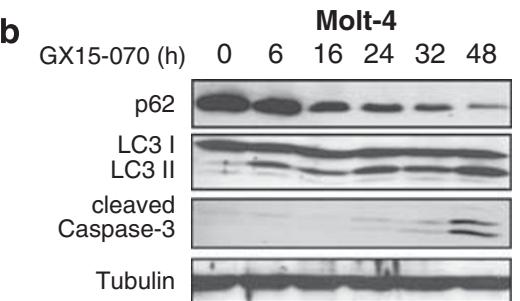

Figure 4 Autophagy is initiated before apoptosis by GX15-070 treatment. (a) CEM, Reh, HSB-2, or Jurkat cells were treated with $100 \mathrm{nM} \mathrm{GX15-070} \mathrm{for} \mathrm{the}$ indicated times. LC3 conversion and caspase-3 cleavage were determined by western blot analyses. (b) Molt- 4 cells were treated with $100 \mathrm{nM} \mathrm{GX15-070} \mathrm{for} \mathrm{the}$ indicated times. LC3 conversion and degradation of p62 as well as caspase-3 cleavage were demonstrated by western blot analyses
Downregulation of BAK, but not BAX, significantly inhibited apoptosis judged by Annexin $\mathrm{V}$-positive population (Figure 6a) and caspase-3 cleavage (Figure 6b), suggesting that GX15-070-induced apoptosis is BAK-dependent. Taken together, these results indicate that GX15-070-induced apoptosis is initiated by the inhibition of MCL-1 binding to BAK, and then the amount of free BAK increases by MCL-1 degradation, which may amplify the apoptotic effect of BAK.

\section{GX15-070-induced autophagy is ATG5-dependent in ALL cells}

We next investigated the molecular mechanisms of GX15-070-induced autophagy. ATG5 is known to function in autophagosome formation and completion. We could not establish the CEM cells in which ATG5 was downregulated, as knocking down of the ATG5 gene itself killed the cells (data not shown). Downregulation of ATG5 in Molt- 4 cells reduced $L C 3$ conversion as well as total cell death induced by GX15-070 treatment (Figure 7a and b). Thus, GX15-070induced autophagy is ATG5-dependent and contributes to cell death.

Beclin-1 is a key regulator of classical autophagy. Downregulation of Beclin-1 reduced GX15-070-induced cell death in both CEM and Molt-4 cells (Figure 8a). However, LC3 conversion was not altered (Figure $8 \mathrm{~b}$ ). The activation of class III phosphoinositide 3-kinase (PI3K III) is essential to induce autophagy through Beclin-1. ${ }^{33,34}$ We thus examined whether inhibition of PI3K III by LY294002 or 3-MA could inhibit autophagy. Neither LY294002 nor 3-MA affected GX15-070mediated LC3 conversion (Supplementary Figure S1a and b). These data suggest that GX15-070-induced autophagy is Beclin-1-independent. a
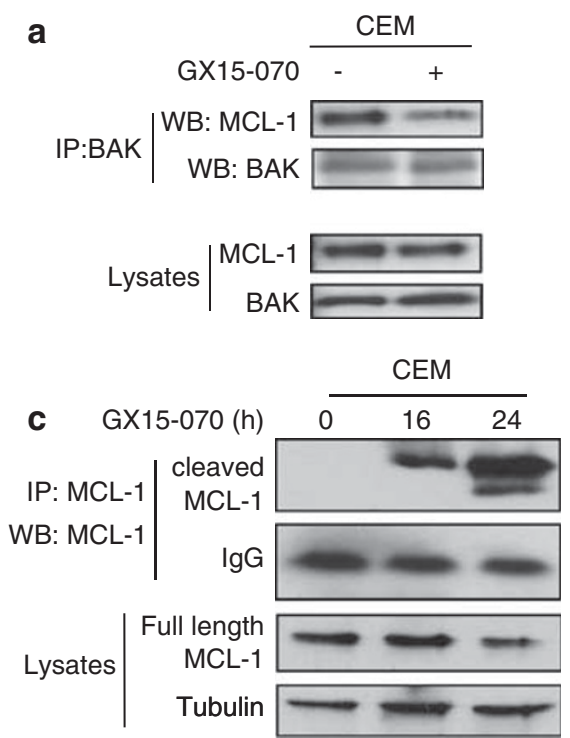

b

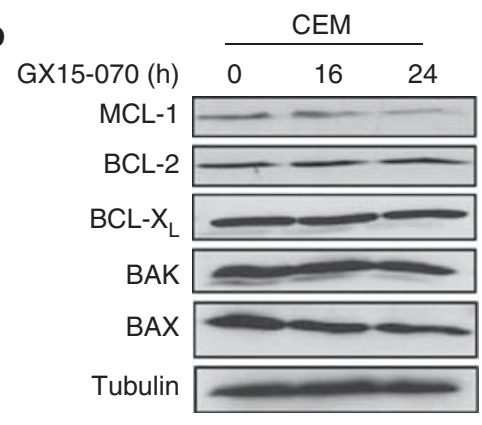

d

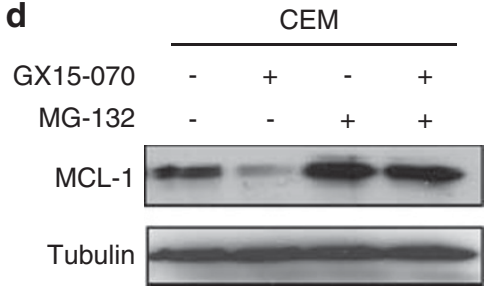

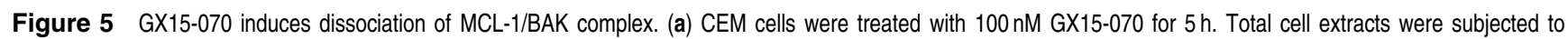
immunoprecipitation with anti-BAK. Western blotting was performed on precipitated samples and on lysates collected before immunoprecipitation with MCL-1 or BAK antibodies. (b) CEM cells were treated with $100 \mathrm{nM}$ GX15-070 for the indicated times and the levels of MCL-1, BCL-2, BCL-X, BAX, and BAK were examined by western blot analysis. (c) CEM cells were treated with $100 \mathrm{nM}$ GX15-070 for the indicated times. Total cell extracts were subjected to immunoprecipitation with anti-MCL-1. Western blotting

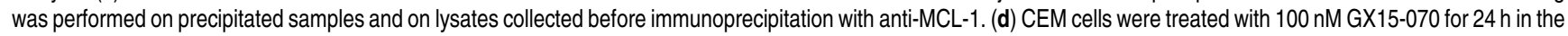
presence or absence of $500 \mathrm{nM} \mathrm{MG-132}$. The level of Mcl-1 was determined by western blot analysis 

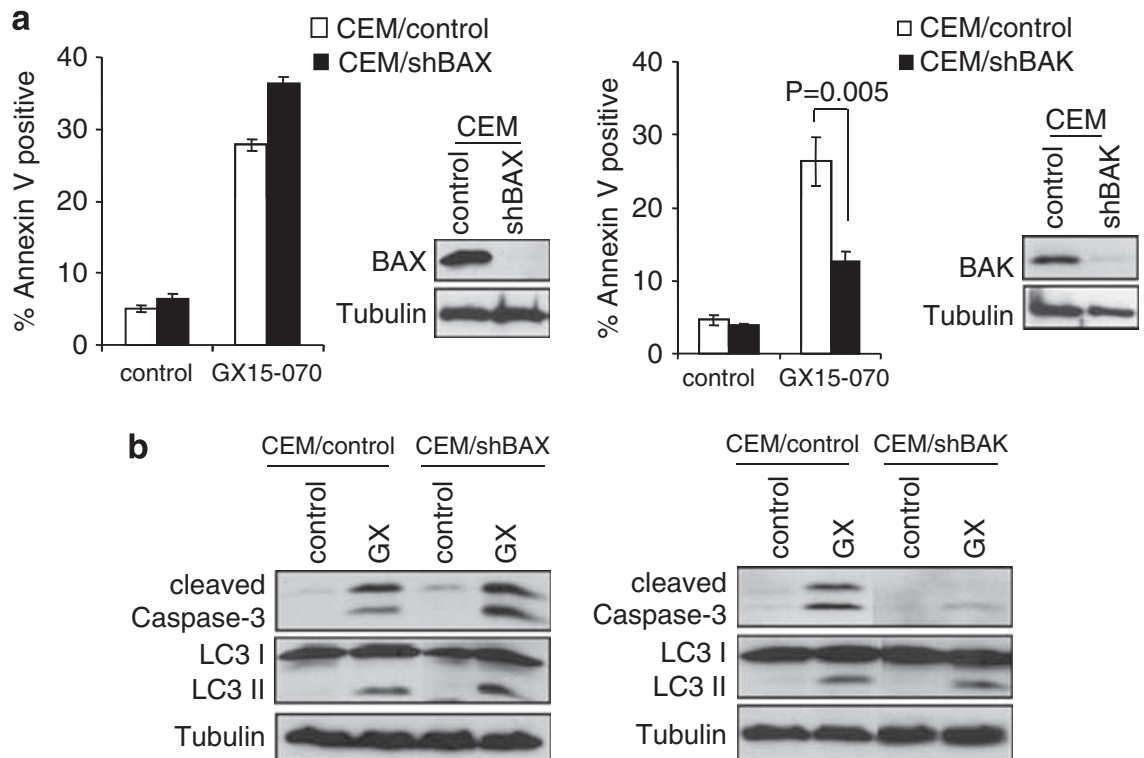

Figure 6 GX15-070-induced apoptosis is BAK-dependent. (a) CEM cells were infected with lentiviruses expressing shRNAs for non-targeting control, BAX, or BAK. Puromycin-resistant cells were pooled after each infection. Downregulation of BAX or BAK expression was monitored by western blotting (in sets). Cells were treated with $100 \mathrm{nM} \mathrm{GX15-070} \mathrm{for} 48 \mathrm{~h}$ and the percentage of cell death was determined by Annexin V-PI staining followed by FACS analysis. Values represent the mean \pm S.D. of three

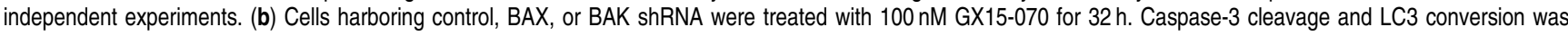
determined by western blot analysis
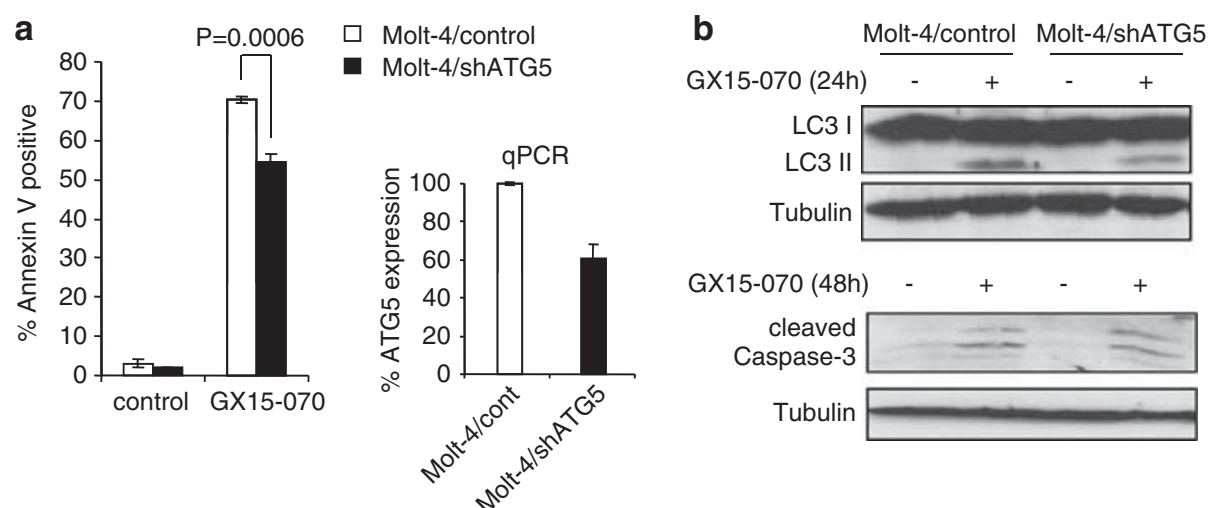

Figure 7 Downregulation of ATG5 decreases autophagy-mediated cell death induced by GX15-070 treatment. (a) Molt-4 cells were infected with lentiviruses expressing shRNAs for either non-targeting control or ATG5. Puromycin-resistant cells were pooled after each infection. Downregulation of ATG5 mRNA was monitored by q-PCR (bottom panel). Cells were treated with $100 \mathrm{nM} \mathrm{GX15-070} \mathrm{for} 72 \mathrm{~h}$ and the percentage of cell death was determined by Annexin V-PI staining followed by FACS analysis. Values represent the mean \pm S.D. of three independent experiments. (b) Cells were treated with $100 \mathrm{nM} \mathrm{GX15-070} \mathrm{for} \mathrm{the} \mathrm{indicated} \mathrm{times,} \mathrm{and} \mathrm{LC3} \mathrm{conversion} \mathrm{and} \mathrm{caspase-3}$ cleavage was assessed by western blot analyses

\begin{abstract}
Apoptosis and autophagy induced by GX15-070 treatment are independently regulated. We next addressed whether there is any crosstalk between apoptosis and autophagy induced by GX15-070 treatment. Our results show that when apoptosis was reduced by downregulation of BAK, LC3 conversion was not affected (Figure 6a and b). In contrast, caspase-3 cleavage was not altered by downregulation of ATG5 when autophagy was reduced (Figure $7 \mathrm{~b}$ ), suggesting that apoptosis and autophagy are independently regulated by GX15-070 treatment.

Beclin-1, an autophagy regulator, is also known to physically interact with $\mathrm{BCL}-2$ and $\mathrm{BCL}-\mathrm{X}_{\mathrm{L}}$ as a $\mathrm{BH}$-only
\end{abstract}

protein, suggesting that Beclin-1 could mediate crosstalk between autophagy and apoptosis pathways. Although GX15-070-induced autophagy was not affected by downregulation of Beclin-1 in CEM and Molt-4 cells, the amount of cell death was decreased (Figure $8 a$ and $b$ ). We thus examined the role of Beclin-1 in the apoptosis pathway. In the case of CEM cells, downregulation of Beclin- 1 reduced the amount of caspase-3 cleavage induced by GX15-070, suggesting that caspase-dependent apoptosis is partly regulated by Beclin-1 (Figure 8b). We did not observe any changes in the amount of AIF released after Beclin-1 knockdown in CEM cells (data not shown). On the contrary, Beclin-1 downregulation did not alter GX15-070-induced 

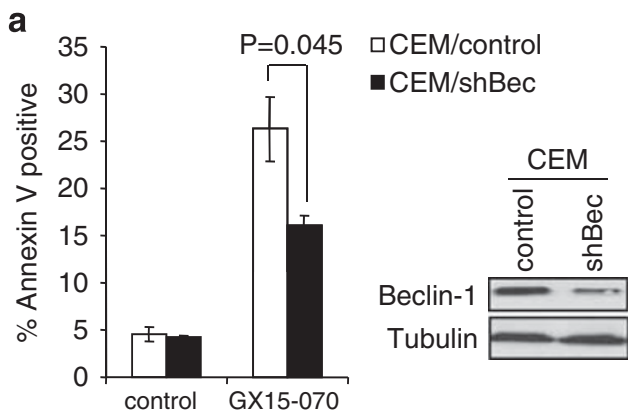

b

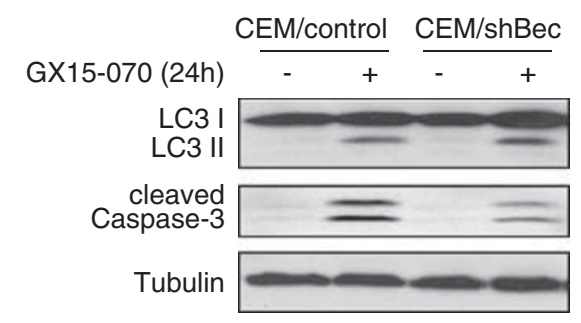

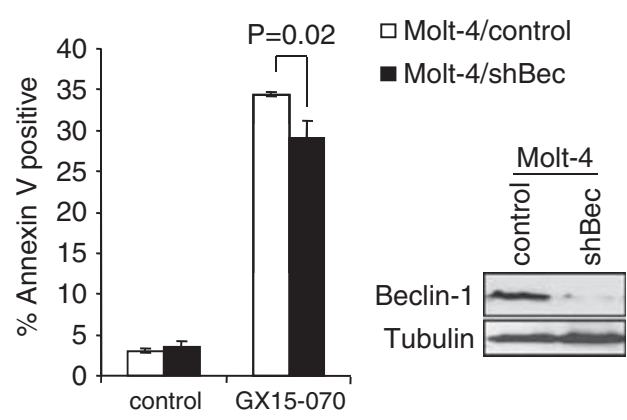

Molt-4/control Molt-4/shBec
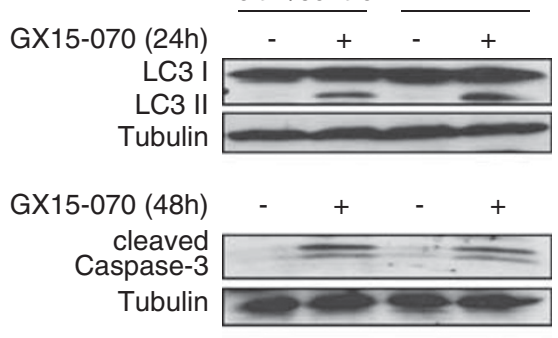

GX15-070 (24h) AIF Tubulin

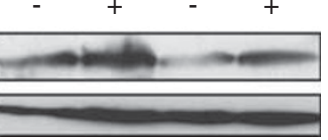

Cytosol fraction

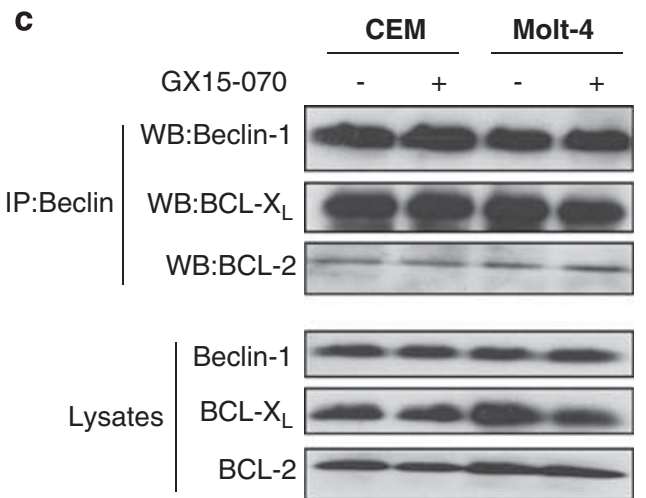

d

Molt-4
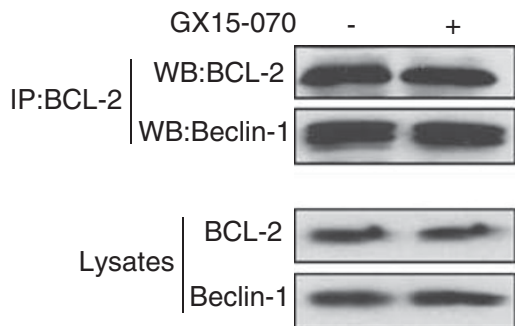

Figure 8 Beclin-1 contributes to GX15-070-induced apoptosis but not to autophagy. (a) CEM or Molt-4 cells were infected with lentiviruses expressing shRNAs for either non-targeting control or Beclin-1 (Bec). Puromycin-resistant cells were pooled after each infection. Downregulation of Beclin-1 expression was monitored by western blotting (in sets). Cells were treated with $100 \mathrm{nM} \mathrm{GX15-070} \mathrm{for} 48 \mathrm{~h}$ and the percentage of cell death was determined by Annexin V-PI staining followed by FACS analysis. Values

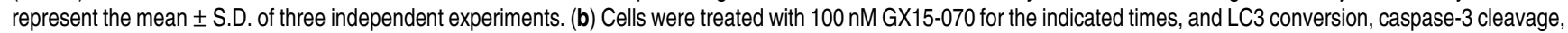

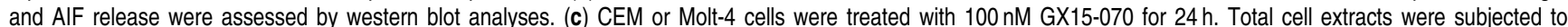
immunoprecipitation with anti-Beclin-1. Western blotting was performed on precipitated samples and on lysates collected before immunoprecipitation with Beclin-1, BCL-2, or BCL- $\mathrm{X}_{\mathrm{L}}$ antibodies. (d) Reciprocal immunoprecipitation was performed with anti-BCL-2. Western blotting was conducted on precipitated samples and on lysates collected before immunoprecipitation with BCL-2 or Beclin-1 antibodies

caspase- 3 cleavage in Molt- 4 cells while AIF release was decreased, suggesting that caspase-independent apoptosis is also regulated by Beclin-1 expression (Figure $8 \mathrm{~b}$ ). To further examine the role of Beclin-1 in crosstalk between autophagy and apoptosis, we determined the interactions of Beclin-1 with BCL-2, Beclin-1 with BCL- $\mathrm{X}_{\mathrm{L}}$, and Beclin-1 with MCL-1 following GX15-070 treatment. Co-immunoprecipitation with anti-Beclin-1 followed by western blot with anti-BCL-2 or anti-BCL- $X_{L}$ revealed that the interactions were not altered by $\mathrm{GX15-070}$ in both CEM and Molt-4 cells (Figure $8 \mathrm{c}$ ). However, we could not detect any interaction of Beclin-1 with MCL-1 in both cell lines (data not shown). Reciprocal co-immunoprecipitation with anti-BCL-2 followed by western blot with anti-Beclin-1 confirmed the interaction of Beclin-1 with BCL-2 without any alteration by GX15-070 treatment (Figure 8d). Taken together, these results suggest that Beclin-1 does not have a role in inducing autophagy by GX15-070, but has a substantial role in GX15-070-induced apoptosis.

\section{Discussion}

GCs have been used in chemotherapy for leukemia, lymphoma, and myeloma for decades. Although they are effective in the initial stages, resistance on relapse often 
emerges. The molecular mechanisms of sensitivity/resistance to this agent are still not fully understood. In this study, we propose a possible strategy to overcome GC resistance in ALL by targeting downstream molecules of the GC receptor, such as the BCL-2 family proteins. We hypothesized that targeting antiapoptotic MCL-1 might be effective among the BCL-2 family proteins, as (1) we recognized that treatment with Dex in CEM or Molt-4 cells slightly induces MCL- $1^{9}$ and that the expression level of MCL-1 is higher in Dex-resistant ALL cells than in Dex-sensitive cells (Supplementary Figure S2); (2) recent studies have demonstrated that increased expression of MCL-1 is associated with GC resistance. ${ }^{13-15}$ In support of our hypothesis, downregulation of MCL-1 by shRNA enhanced Dex-induced cell death (Figure 1). We then

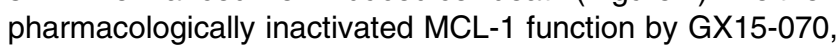
a $\mathrm{BH} 3$ mimetic small molecule that targets antiapoptotic BCL-2 family proteins including BCL-2, BCL- $\mathrm{X}_{\mathrm{L}}$, and $\mathrm{MCL}-1$. Treatment with $\mathrm{GX15-070}$ induced caspase-3 cleavage and increased the Annexin V-positive population, which is indicative of apoptosis. It has been shown that GX15-070 binds to MCL-1 and inhibits the binding with BAK, ${ }^{19}$ which leads to apoptosis. Consistent with the previous findings, dissociation of BAK/MCL-1 complex was detected $5 \mathrm{~h}$ after GX15-070 treatment. We also observed dramatic degradation of $\mathrm{MCL}-1$ at later time points in a proteasome-dependent manner. These results suggest that BAK activation is initiated by the release from MCL-1 and probably is amplified by MCL-1 degradation. Downregulation of BAK reduced caspase-3 cleavage and cell death, but did not alter LC3 conversion, indicating that apoptosis but not autophagy is regulated by BAK.

Before the onset of apoptosis and as early as $6 \mathrm{~h}$ after the treatment, GX15-070 induced LC3 conversion as well as p62 degradation, which is indicative of autophagy. Downregulation of ATG5 decreased LC3 conversion and cell death, but did not alter caspase-3 cleavage. These data suggest that GX15-070-induced autophagy contributes to cell death but is not a pre-requisite for commitment to apoptosis. Thus, ATG5-dependent autophagy and BAK-dependent apoptosis are independently regulated by GX15-070 treatment. Furthermore, our data suggest that GX15-070-induced autophagy is executed by the Beclin-1-independent pathway. Downregulation of Beclin-1 did not alter LC3 conversion induced by GX15-070 treatment (Figure 8b). We can come to the same conclusion by using LY294002 and 3-MA, inhibitors of PI3K that are required for autophagy induction through Beclin-1. Neither LY29002 nor 3-MA affected GX15-070-mediated LC3 conversion (Supplementary Figure S1). Although GX15-070induced autophagy was not affected by downregulation of Beclin-1, the amount of cell death decreased. This reduction of cell death is mediated through apoptosis, as caspase-3 cleavage or AIF release was decreased by downregulation of Beclin-1. It has been recently shown that after initiating apoptosis, Beclin-1 is cleaved by caspases and the N-terminal fragment of Beclin-1 can inhibit autophagy while the C-terminal fragment can amplify mitochondrial-mediated apoptosis, ${ }^{35}$ suggesting that Beclin- 1 has dual function as a regulator of autophagy and apoptosis. In contrast to this finding, the level of full-length Beclin-1 was constant following GX15-070 treatment, even though caspase-3 was already active (data not shown). Of note, a recent report described that autophagy is induced after Dex treatment in Dexsensitive ALL cells. ${ }^{36}$ However, we could not detect LC3 conversion in CEM cells after Dex treatment when caspase-3 cleavage was clearly observed (Figure 3c). Furthermore, we showed before that the amount of Dex-induced cell death was not altered by co-treatment with LY294002, ${ }^{12}$ and that co-treatment with Dex and GX15-070 showed an additive effect compared with each treatment alone (Figure $2 b$ ). Therefore, GX15-070-induced cell death pathways are distinct and independent of the Dex-induced cell death pathway.

Recently, Bonapace et al. ${ }^{28}$ demonstrated that GX15-070 re-sensitizes GC-resistant ALL cells. Our results demonstrate that single treatment with a low dose of GX15-070 (i.e., $100 \mathrm{nM}$ ) sufficiently induces growth inhibition and cell death by inducing BAK-dependent apoptosis and ATG5-dependent autophagy. The authors observed dissociation of the Beclin-1/MCL-1 complex with GX15-070 treatment. In contrast, we could not detect the Beclin-1/MCL-1 complex in CEM, Molt-4 and Jurkat cells (data not shown), with the same conditions under which we clearly observed Beclin-1/ $B C L-2$ and Beclin-1/BCL- $X_{L}$ interaction (Figure $8 c$ and $d$ ), probably because of the amount of existing complex in the cells. A previous report also showed that the interaction of MCL-1 and Beclin-1 is not as strong as that between Beclin-1 and BCL-2 and between Beclin-1 and BCL- $X_{L} .{ }^{37}$ Thus, further investigation is required to clarify the mechanism required to initiate GX15-070-induced autophagy.

Enhanced expression levels of antiapoptotic BCL-2 family protein have been observed in several types of tumors. Targeting these proteins is therefore an attractive strategy for restoring the apoptosis process in tumor cells. Among the small-molecule BCL-2 inhibitors, ABT-737 and its analog ABT-263 are the leading compounds that are currently in clinical development. However, these molecules have an affinity only for $B C L-2$ and $B C L-X_{L}$, but not for $M C L-1$. Thus, ABT-737 cannot be effective as a single-agent therapeutic for ALL when MCL-1 is overexpressed. ${ }^{17,38}$ In contrast, GX15-070 can overcome the resistance conferred by high levels of MCL-1. Our results suggest that GX15-070 could be useful as a single-agent therapeutic against ALL and that the activity/expression of antiapoptotic proteins could be a biomarker to determine the treatment strategy for ALL patients.

\section{Materials and methods}

Cell lines and culture. CCRF-CEM, Molt-4, HSB-2, Reh, and Jurkat cells were purchased from the American Tissue Culture Collection (Manassas, VA, USA). Cells were cultured in RPMI 1640 supplemented with $10 \%$ heat-inactivated fetal bovine serum, $1 \mathrm{mM}$ sodium pyruvate, streptomycin, and penicillin $\mathrm{G}$ at $37^{\circ} \mathrm{C}$ in a humidified, $5 \% \mathrm{CO}_{2}$ incubator.

Chemicals and antibodies. Dex was purchased from Sigma (St Louis, MO, USA). GX15-070 was provided from Gemin X (Montreal, Quebec, Canada). MG-132 was purchased from Calbiochem (San Diego, CA, USA). The antibodies used for western blot and immunoprecipitation were as follows: BAX (N-20), $\alpha$-tubulin, $\beta$-tubulin and AIF from Santa Cruz Biotechnology (Santa Cruz, CA, USA); BAK from Upstate/Millipore (Billerica, MA, USA); BCL-2 from Sigma; MCL-1 from Assay Designs (Ann Arbor, MI, USA); BIM, BCL- $X_{L}$, Beclin-1, ATG5 and caspase-3 from Cell Signaling Technology (Beverly, MA, USA); cytochrome $c$ and $p 62$ from BD-Pharmingen (San Diego, CA, USA); Beclin-1 and LC3 from Novus Biologicals 
(Littleton, CO, USA); PARP from Oncogene (Darmstadt, Germany); WST-1 reagent from Roche (Mannheim, Germany); and Z-VAD-FMK from ALEXIS Biochemicals (Lausen, Switzerland).

Lentivirus infection and plasmid transfection. The lentiviral shorthairpin RNA (shRNA)-expressing constructs were purchased from Open Biosystems (Huntsville, AL, USA). The constructs were transfected into 293T packaging cells along with the packaging plasmids, and the lentivirus-containing supernatants were used to transduce ALL cells. The RFP-LC3 construct was kindly provided by Dr. David Gewirtz (VCU). Transfection was performed by electroporation using a Bio-Rad electroporator (Hercules, CA, USA). The cells were suspended in RPMl $1640\left(4 \times 10^{6} / 400 \mu \mathrm{l}\right)$ with $10 \mu \mathrm{g}$ of DNA and electroporated in $0.4-\mathrm{cm}$ cuvettes at $300 \mathrm{~V}$ and $500 \mu \mathrm{F}$. Puromycin $(2 \mu \mathrm{g} / \mathrm{ml}$ for shRNAs) or G418 (800 $\mu \mathrm{g} / \mathrm{ml}$ for RFP-LC3) selection to establish stable cells began $24 \mathrm{~h}$ after virus infection or electroporation.

Quantitative RT-PCR. Total RNA was extracted by Trizol (Invitrogen, Carlsbad, CA, USA) from Molt-4 cells infected with shATG5-containing lentivirus. In all, $1 \mu \mathrm{g}$ of RNA was reverse-transcribed by using the High Capacity cDNA Reverse Transcription kit (Applied Biosystems) according to the manufacturer's instructions. Using Taqman Gene Expression Assay probe/primer Hs00169468 (Applied Biosystems, Foster City, CA, USA), cDNAs were amplified in a fluorescence thermocycler (Applied Biosystems 7500HT Fast Real-time PCR system) and were analyzed based on the expression level of GADPH with SDS2.2 software.

Immunoprecipitation and western blot analyses. Whole-cell lysates were prepared with CHAPS lysis buffer (20 mM Tris (pH 7.4), $137 \mathrm{mM} \mathrm{NaCl}, 1 \mathrm{mM}$ dithiothreitol (DTT), 1\% CHAPS (3-((3-cholamidopropyl)dimethylammonio)-1propanesulfonate), $20 \mathrm{mM} \mathrm{NaF}, 10 \mathrm{mM} \beta$-glycerophosphate, and a protease inhibitor cocktail (Sigma)). For immunoprecipitation, equal amounts of protein were incubated with the appropriate antibody for $3 \mathrm{~h}$ on ice. Then antibody complexes were captured with protein A/G beads (Pierce, Rockford, IL, USA), at $4^{\circ} \mathrm{C}$ for $1 \mathrm{~h}$ with rotation. After washing three times with the same lysis buffer, the beads were re-suspended in the sample buffer and the samples were separated by SDS-PAGE. For western blot analyses, equal amounts of proteins were loaded on SDS-PAGE, transferred to a nitrocellulose membrane and analyzed by immunoblotting.

Cell viability assay. Cell proliferation was measured by WST-1 assay. $10^{4}$ CEM, Reh or HSB-2 and $5 \times 10^{3}$ Jurkat or Molt- 4 cells were cultured in $100 \mu \mathrm{l} \mathrm{RPMl}$ and treated with $100 \mathrm{nM}$ GX15-070 for 1-4 days. WST-1 $(5 \mu \mathrm{l})$ was added to samples and they were incubated for $3 \mathrm{~h}$ at $37^{\circ} \mathrm{C}$ and in $5 \% \mathrm{CO}_{2}$. Absorbance of triplicate samples at $450 \mathrm{~nm}$ was measured by a multilabel reader (PerkinElmer, Shelton, CT, USA).

Cell death was quantified by Annexin V-FITC or -APC (BD Pharmingen) and propidium iodide (Sigma) staining according to the manufacturer's protocol, followed by flow-cytometric analysis using FACScan (BD Biosciences).

Subcellular fractionation. Two million cells were washed in PBS and lysed by incubating for $30 \mathrm{~s}$ at room temperature in digitonin lysis buffer $(75 \mathrm{mM} \mathrm{NaCl}$, $8 \mathrm{mM} \mathrm{Na}_{2} \mathrm{HPO}_{4}, 1 \mathrm{mM} \mathrm{NaH}_{2} \mathrm{PO}_{4}, 1 \mathrm{mM}$ EDTA, and $350 \mu \mathrm{g} / \mathrm{ml}$ digitonin). Lysates were centrifuged $(\times 12000 \mathrm{~g})$ for $1 \mathrm{~min}$, and the supernatant (cytosolic fraction) was collected. Pellets (membrane fractions) were washed once in cold PBS and lysed in CHAPS lysis buffer. The cytosolic and membrane samples were quantified, separated by SDS-PAGE, and subjected to western blot analysis.

Fluorescent microscopy. CEM cells stably expressing RFP-LC3 were treated with $100 \mathrm{nM}$ GX15-070 for $24 \mathrm{~h}$. Cells were then analyzed using Olympus $1 \mathrm{X70}$ microscope.

Statistical analysis. Values represent the means \pm S.D. for three separate experiments. The significance of differences between experimental variables was determined using the Student's $t$-test. Values were considered statistically significant at $P<0.05$.

\section{Conflict of interest}

The authors declare no conflict of interest.
Acknowledgements. We thank Gemin $X$ and David Gewirtz (VCU) for providing us GX15-070 (obatoclax) and the RFP-LC3 plasmid, respectively. We also thank Barbara Szomju, and Kristoffer Valerie for lentivirus generation at the VCU Macromolecule Core Facility, which was supported, in part, by $\mathrm{NIH}-\mathrm{NCl}$ Cancer Center Core Grant 5P30CA016059. This work is supported by NIH R01CA134473 and the William Lawrence and Blanche Hughes Foundation.

1. Tissing WJ, Meijerink JP, den Boer ML, Pieters R. Molecular determinants of glucocorticoid sensitivity and resistance in acute lymphoblastic leukemia. Leukemia 2003; 17: 17-25.

2. Schmidt S, Rainer J, Ploner C, Presul E, Riml S, Kofler R. Glucocorticoid-induced apoptosis and glucocorticoid resistance: molecular mechanisms and clinical relevance. Cell Death Differ 2004; 11 (Suppl 1): S45-S55.

3. Bachmann PS, Gorman R, Papa RA, Bardell JE, Ford J, Kees UR et al. Divergent mechanisms of glucocorticoid resistance in experimental models of pediatric acute lymphoblastic leukemia. Cancer Res 2007; 67: 4482-4490.

4. Tissing WJ, Meijerink JP, Brinkhof B, Broekhuis MJ, Menezes RX, den Boer ML et al. Glucocorticoid-induced glucocorticoid-receptor expression and promoter usage is not linked to glucocorticoid resistance in childhood ALL. Blood 2006; 108: 1045-1049.

5. Distelhorst CW. Recent insights into the mechanism of glucocorticosteroid-induced apoptosis. Cell Death Differ 2002; 9: 6-19.

6. Frankfurt $\mathrm{O}$, Rosen ST. Mechanisms of glucocorticoid-induced apoptosis in hematologic malignancies: updates. Curr Opin Oncol 2004; 16: 553-563.

7. Planey SL, Litwack G. Glucocorticoid-induced apoptosis in lymphocytes. Biochem Biophys Res Commun 2000; 279: 307-312.

8. Ploner C, Rainer J, Lobenwein S, Geley S, Kofler R. Repression of the BH3-only molecule PMAIP1/Noxa impairs glucocorticoid sensitivity of acute lymphoblastic leukemia cells. Apoptosis 2009; 14: 821-828.

9. Rambal AA, Panaguiton ZL, Kramer L, Grant S, Harada H. MEK inhibitors potentiate dexamethasone lethality in acute lymphoblastic leukemia cells through the pro-apoptotic molecule BIM. Leukemia 2009; 23: 1744-1754.

10. Youle RJ, Strasser A. The BCL-2 protein family: opposing activities that mediate cell death. Nat Rev Mol Cell Biol 2008; 9: 47-59.

11. Chipuk JE, Moldoveanu T, Llambi F, Parsons MJ, Green DR. The BCL-2 family reunion. Mol Cell 2010; 37: 299-310.

12. Lu J. Quearry B and Harada H, p38-MAP kinase activation followed by BIM induction is essential for glucocorticoid-induced apoptosis in lymphoblastic leukemia cells. FEBS Lett 2006; 580: 3539-3544.

13. Stam RW, Den Boer ML, Schneider P, de Boer J, Hagelstein J, Valsecchi MG et al. Association of high-level MCL-1 expression with in vitro and in vivo prednisone resistance in MLL-rearranged infant acute lymphoblastic leukemia. Blood 2010; 115: 1018-1025.

14. Wei G, Twomey D, Lamb J, Schlis K, Agarwal J, Stam RW et al. Gene expression-based chemical genomics identifies rapamycin as a modulator of MCL1 and glucocorticoid resistance. Cancer Cell 2006; 10: 331-342.

15. Holleman A, Cheok MH, den Boer ML, Yang W, Veerman AJ, Kazemier KM et al. Geneexpression patterns in drug-resistant acute lymphoblastic leukemia cells and response to treatment. N Engl J Med 2004; 351: 533-542.

16. Opferman JT, Green DR. DUB-le trouble for cell survival. Cancer Cell 2010; 17: 117-119.

17. Chonghaile TN, Letai A. Mimicking the BH3 domain to kill cancer cells. Oncogene 2008; 27 (Suppl 1): S149-S157.

18. Kang MH, Reynolds CP. Bcl-2 inhibitors: targeting mitochondrial apoptotic pathways in cancer therapy. Clin Cancer Res 2009; 15: 1126-1132.

19. Nguyen M, Marcellus RC, Roulston A, Watson M, Serfass L, Murthy Madiraju SR et al. Small molecule obatoclax (GX15-070) antagonizes MCL-1 and overcomes MCL-1mediated resistance to apoptosis. Proc Natl Acad Sci USA 2007; 104: 19512-19517.

20. Trudel S, Li ZH, Rauw J, Tiedemann RE, Wen XY, Stewart AK. Preclinical studies of the pan-Bcl inhibitor obatoclax (GX015-070) in multiple myeloma. Blood 2007; 109: 5430-5438.

21. Schimmer AD, O'Brien S, Kantarjian H, Brandwein J, Cheson BD, Minden MD et al. A phase I study of the pan bcl-2 family inhibitor obatoclax mesylate in patients with advanced hematologic malignancies. Clin Cancer Res 2008; 14: 8295-8301.

22. O'Brien SM, Claxton DF, Crump M, Faderl S, Kipps T, Keating MJ et al. Phase I study of obatoclax mesylate (GX15-070), a small molecule pan-Bcl-2 family antagonist, in patients with advanced chronic lymphocytic leukemia. Blood 2009; 113: 299-305.

23. Campas C, Cosialls AM, Barragan M, Iglesias-Serret D, Santidrian AF, Coll-Mulet $L$ et al. Bcl-2 inhibitors induce apoptosis in chronic lymphocytic leukemia cells. Exp Hematol 2006; 34: 1663-1669.

24. Konopleva M, Watt J, Contractor R, Tsao T, Harris D, Estrov Z et al. Mechanisms of antileukemic activity of the novel Bcl-2 homology domain-3 mimetic GX15-070 (obatoclax). Cancer Res 2008; 68: 3413-3420.

25. Vogler M, Weber K, Dinsdale D, Schmitz I, Schulze-Osthoff K, Dyer MJ et al. Different forms of cell death induced by putative BCL2 inhibitors. Cell Death Differ 2009; 16: 1030-1039.

26. Martin AP, Mitchell C, Rahmani M, Nephew KP, Grant S, Dent P. Inhibition of MCL-1 enhances lapatinib toxicity and overcomes lapatinib resistance via BAK-dependent autophagy. Cancer Biol Ther 2009; 8: 2084-2096. 
27. Jiang CC, Wroblewski D, Yang F, Hersey $P$, Zhang XD. Human melanoma cells under endoplasmic reticulum stress are more susceptible to apoptosis induced by the $\mathrm{BH} 3$ mimetic obatoclax. Neoplasia 2009; 11: 945-955.

28. Bonapace L, Bornhauser BC, Schmitz M, Cario G, Ziegler U, Niggli FK et al. Induction of autophagy-dependent necroptosis is required for childhood acute lymphoblastic leukemia cells to overcome glucocorticoid resistance. J Clin Invest 2010; 120: 1310-1323.

29. Mizushima N, Yoshimori T, Levine B. Methods in mammalian autophagy research. Cell 2010; 140: 313-326.

30. Levine B, Sinha S, Kroemer G. Bcl-2 family members: dual regulators of apoptosis and autophagy. Autophagy 2008; 4: 600-606.

31. Ploner C, Rainer J, Niederegger H, Eduardoff M, Villunger A, Geley S et al. The BCL2 rheostat in glucocorticoid-induced apoptosis of acute lymphoblastic leukemia. Leukemia 2008; 22: 370-377.

32. Willis SN, Chen L, Dewson G, Wei A, Naik E, Fletcher $\mathrm{Jl}$ et al. Proapoptotic Bak is sequestered by $\mathrm{Mcl}-1$ and $\mathrm{Bcl}-\mathrm{xL}$, but not $\mathrm{Bcl}-2$, until displaced by $\mathrm{BH} 3-$ only proteins. Genes Dev 2005; 19: 1294-1305.

33. Sinha S, Colbert CL, Becker N, Wei Y, Levine B. Molecular basis of the regulation of Beclin 1-dependent autophagy by the gamma-herpesvirus $68 \mathrm{Bcl}-2$ homolog M11. Autophagy 2008; 4: 989-997.

34. Kihara A, Kabeya Y, Ohsumi Y, Yoshimori T. Beclin-phosphatidylinositol 3-kinase complex functions at the trans-Golgi network. EMBO Rep 2001; 2: 330-335.
35. Wirawan E, Vande Walle L, Kersse K, Cornelis S, Claerhout S, Vanoverberghe I et al. Caspase-mediated cleavage of Beclin-1 inactivates Beclin-1-induced autophagy and enhances apoptosis by promoting the release of proapoptotic factors from mitochondria. Cell Death Dis 2010; 1: e18.

36. Laane E, Tamm KP, Buentke E, Ito K, Kharaziha P, Oscarsson J et al. Cell death induced by dexamethasone in lymphoid leukemia is mediated through initiation of autophagy. Cell Death Differ 2009; 16: 1018-1029.

37. Erlich S, Mizrachy L, Segev O, Lindenboim L, Zmira O, Adi-Harel S et al. Differential interactions between Beclin 1 and Bcl-2 family members. Autophagy 2007; 3: 561-568.

38. High LM, Szymanska B, Wilczynska-Kalak U, Barber N, O'Brien R, Khaw SL et al. The $\mathrm{Bcl}-2$ homology domain 3 mimetic ABT-737 targets the apoptotic machinery in acute lymphoblastic leukemia resulting in synergistic in vitro and in vivo interactions with established drugs. Mol Pharmacol 2010; 77: 483-494.

\section{(c)}

SOMERIGHTS RESERV

Cell Death and Disease is an open-access journal published by Nature Publishing Group. This work is licensed under the Creative Commons Attribution-Noncommercial-No Derivative Works 3.0 Unported License. To view a copy of this license, visit http://creativecommons.org/licenses/by-nc-nd/3.0/

Supplementary Information accompanies the paper on Cell Death and Disease website (http://www.nature.com/cddis) 